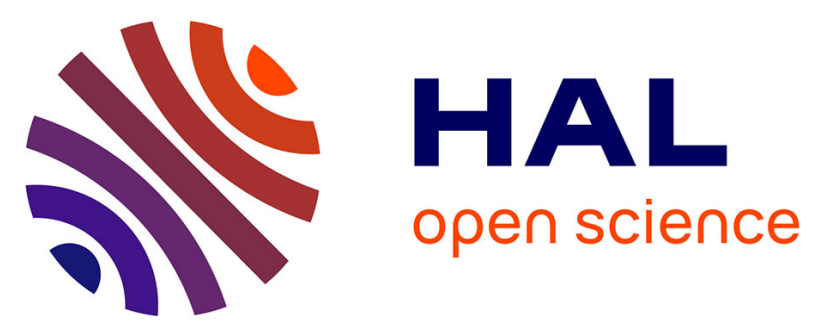

\title{
High-silica mordenite as scaffold for phenylacetylene polymerization: In situ high pressure investigation
}

Giorgia Confalonieri, Marco Fabbiani, Rossella Arletti, Simona Quartieri, Francesco Di Renzo, Julien Haines, Gloria Tabacchi, Ettore Fois, Giovanna Vezzalini, Gianmario Martra, et al.

\section{To cite this version:}

Giorgia Confalonieri, Marco Fabbiani, Rossella Arletti, Simona Quartieri, Francesco Di Renzo, et al.. High-silica mordenite as scaffold for phenylacetylene polymerization: In situ high pressure investigation. Microporous and Mesoporous Materials, 2020, 300, pp.110163. 10.1016/j.micromeso.2020.110163 . hal-02617418

\section{HAL Id: hal-02617418 \\ https://hal.umontpellier.fr/hal-02617418}

Submitted on 12 Nov 2020

HAL is a multi-disciplinary open access archive for the deposit and dissemination of scientific research documents, whether they are published or not. The documents may come from teaching and research institutions in France or abroad, or from public or private research centers.
L'archive ouverte pluridisciplinaire HAL, est destinée au dépôt et à la diffusion de documents scientifiques de niveau recherche, publiés ou non, émanant des établissements d'enseignement et de recherche français ou étrangers, des laboratoires publics ou privés. 


\section{High-silica mordenite as scaffold for phenylacetylene polymerization: In situ high pressure investigation}

GiorgiaConfalonieriaMarcoFabbianibRossellaArlettiaSimonaQuartieriaFrancescoDi

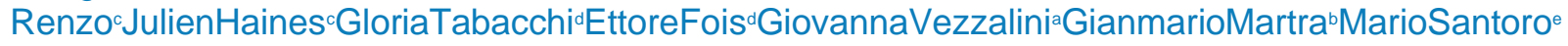
Show more

\section{Abstract}

The joint use of high pressure and regular void-space architectures is a promising route to obtain new nanomaterials with unique properties. We explore herein the pressure-driven injection of aromatic guest species inside zeolite mordenite. Monomeric phenylacetylene ( $\mathrm{PhA})$, used as pressure transmitting medium, was inserted in high-silica mordenite at high pressure conditions. In-situ X-ray powder diffraction and IR spectroscopy analyses show that the combined action of high pressure, temperature and zeolite pores accomplish the intrusion of phenylacetylene and its conversion to oligomeric species exhibiting a greater degree of conjugation with respect to the starting monomer. This study may open a new path for the realization of composite materials with interesting optoelectronic properties via pressure-driven intrusion and polymerization of aromatic molecules inside zeolite frameworks.

\section{Graphical abstract}
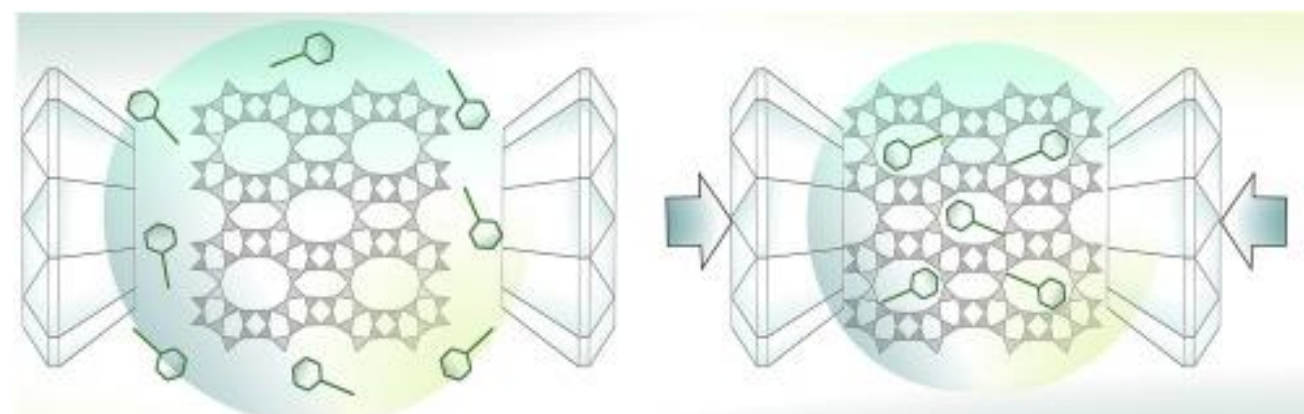

Phenylacetylene molecules penetration and reaction in Si-Mordenite by using high pressure

\section{Keywords}


Pure-silica mordenite

High-pressure

Hydrocarbon-polymerization

\section{Introduction}

Zeolite materials, thanks to their unique properties, related to their composition and pore topology, are of paramount importance in many technological processes, such as catalysis, adsorption, separation and ion exchange [[1], [2], [3], [4]].

Due to their structure, zeolites pores can be filled by suitable guest molecules (organic or inorganic) and cations, more or less able to diffuse in the pores [ $\underline{5}, \underline{6}]$. Their level of hydrophilicity/hydrophobicity, thus the fate of the competitive adsorption of $\mathrm{H}_{2} \mathrm{O}$ molecules $v s$ other molecules can be modulated by varying their $\mathrm{SiO}_{2} / \mathrm{Al}_{2} \mathrm{O}_{3}$ ratio. Thanks to their void architecture, zeolites can also be adopted as "moulds" for creating regular arrays of molecules to develop functional materials [ 6 ], such as: (i) semiconductor quantum dots and wires [7]; (ii) artificial antenna systems constituted by wires of organic dyes running along the zeolite mono-dimensional channel system [8,9]; (iii) luminescent materials obtained by the insertion of lanthanide arrays in the zeolite channels [10]; (iv) effect pigments [11]. Moreover, by operating at high pressure (HP) conditions, novel supramolecular arrangements can be produced by the zeolite "mould" $[\underline{12}, \underline{13}]$.

Once the pores are filled, reactions can be initiated and controlled inside the zeolite's cavities. It has been demonstrated that HP is an ideal tool for implementing chemical reactions induced by purely mechanical methods, by tuning the intermolecular/interatomic distances and causing a rearrangement of chemical bonds. The nano-confinement, deriving from the combination of HP with the geometrical constraints imposed by the zeolitic framework, has proven to be effective in driving the formation of polymers with desired dimensionality, such as polyethylene [14], polyacetylene [15] and polycarbonyl [16]. Preparing isolated, self-standing, densely packed polymers, protected by a hydrophobic matrix, is very challenging via conventional protocols $[\underline{17}, \underline{18}]$.

Here, we exploit the porous template effectiveness of zeolites to investigate for the first time the reactivity, under HP conditions, of a molecule containing an aromatic 
moiety. In particular, we focalize our efforts on the incorporation of phenylacetylene ( $\mathrm{PhA})$ in a high-silica phase of zeolite mordenite (HS-MOR). Our choice is due to the fact that, in most of the zeolite-based devices, guest species are generally characterized by high optical absorbance properties [[7], [8], [9], [10], [11]]. Hence, the presence of an aromatic ring in $\mathrm{PhA}$ might help to impart interesting optoelectronic properties to the zeolite-based composite material, which might be exploited in new devices for practical applications - like, for example, gas sensing [19].

By injecting monomeric $\mathrm{PhA}$ molecules as pressure transmitting medium inside a high-silica mordenite and following their behaviour under HP, in this work we provide evidence of the nearly-complete disappearance of phenylacetylene in favour of the formation of encapsulated carbocationic poly-PhA oligomers.

\section{Materials and methods}

\subsection{Materials}

A high silica mordenite (purchased from the Tosoh Corporation - code HSZ-690HOA Tosoh - in its protonated form, $\mathrm{Si} / \mathrm{Al} \sim 200$, i.e. ca. $0.5 \mathrm{Al}$ per unit cell, HS-MOR hereafter) was selected as the host material, considering the following specific needs: (i) its pore dimensions allow the penetration of the molecules of interest; (ii) the framework has a mono-dimensional channel system, suitable to promote the synthesis of 1D isolated polymer chains; (iii) the connection among the channels will allow the gas circulation. This latter is a crucial point for the realization of a gas sensing device: an effective gas circulation requires mono-dimensional non-intersecting - but communicating - parallel channels with different diameter, one larger channel in which the polymerization will be realized, and one smaller channel for gas diffusion. The contact between the parallel channels is ensured in MOR topology by sufficiently large windows between them.

Mordenite: Mordenite (framework type MOR [20], space group $\mathrm{Cmcm}$ ) crystal structure exhibits a 1D channel system characterized by two parallel channels running along the $c$ axis: a large almost circular 12 MR channels ('free diameters"' $6.5 \AA \times 7.0 \AA$ ) and a strongly elliptic 8 MR channels ('free diameters"' $2.6 \AA 5.7 \AA$ ). These channels are interconnected along the [010] direction through 
side pockets delimited by two $8 \mathrm{MR}$ apertures that, in turn, form a sinusoidal channel ('free diameters"' $3.4 \AA \times 4.8 \AA$ ) running along the $b$ axis [21]. As a whole, two $12 \mathrm{MR}$ and two $8 \mathrm{MR}$ are present in a single unit cell.

The pristine material has been fully characterized and previously used in a number of studies [[22], [23], [24]]. A representation of MOR framework and structural data of the pristine HS-MOR here used are reported in Fig. 1 and in Table 1, respectively.
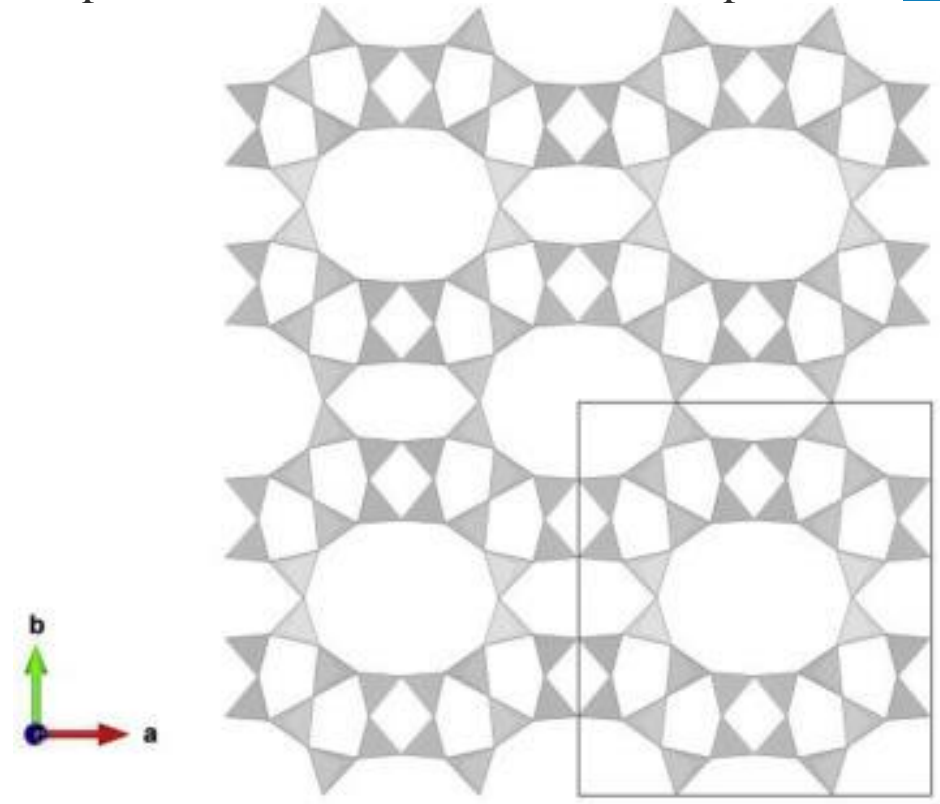

Fig. 1. MOR framework structure viewed along the [001] direction. Unit cell is drawn.

Table 1. Data relative to the pristine HS-MOR used for phenylacetylene loading. *taken from the structural refinement reported in Ref. [23].

\section{HS-MOR}

$\mathrm{SiO}_{2} / \mathrm{Al}_{2} \mathrm{O}_{3}$

Space group

$a(\AA)$

$b(\AA)$

$c(\AA)$

$V\left(\AA^{3}\right)$

$\mathrm{H}_{2} \mathrm{O}$ molecules p.u.c.* (material exposed to air) $\sim 200$

$\mathrm{Cmcm}$

$18.0519(8)$

$20.2061(8)$

$7.4506(3)$

$2717.7(2)$

3.6

98\% pure Phenylacetylene: Pure phenylacetylene (PhA hereafter) purchased by Sigma Aldrich.

\subsection{Pore dimensions evaluation}


Textural properties were evaluated by $\mathrm{N}_{2}$ adsorption at $77 \mathrm{~K}$ in a vacuum-improved Micromeritics Tristar apparatus after outgassing at $250{ }^{\circ} \mathrm{C}$. Mesopore volume was measured by the $\alpha \mathrm{S}$ method and mesopore size distribution was evaluated by the DFT method.

\subsection{High pressure experiments}

To unravel the formation of PhA polymer inside HS-MOR and its stability inside zeolite channels, the guest-guest and host-guest interactions were investigated by in situ HP X-ray powder diffraction experiments (HP-XRPD) and HP Infrared Spectroscopy (HP-IR) experiments.

\subsubsection{HP-XRPD}

Some preliminary patterns were collected on a conventional diffractometer (Mo K $\alpha$ Radiation), but data quality allows only qualitative considerations on pore filling (see below), so all the HP-XRPD experiments were collected at synchrotron facilities.

HP - XRPD experiments were performed at the beamline BM01, ESRF (European Synchrotron Radiation Facility, Grenoble France) using a modified Merrill-Basset Diamond Anvil Cell [25]. Pressure was calibrated using the ruby fluorescence method [26] on a nonlinear hydrostatic pressure scale (the estimated error is $0.05 \mathrm{GPa}$ ) [27]. Pure PhA was used as penetrating Pressure Transmitting Medium (PTM). The experiments were performed in Debye Scherrer geometry with a fixed wavelength of $0.68202 \AA$ A Diffraction intensities were collected on a Pilatus Dectris detector (with pixel dimensions of $172 \mu \mathrm{m} \times 172 \mu \mathrm{m}$ ) positioned at a fixed distance of $238.98 \mathrm{~mm}$ from the sample. Pressure was increased up to $1.34 \mathrm{GPa}$ and then the pressurized DAC was kept in oven at $150{ }^{\circ} \mathrm{C}$ for $5 \mathrm{~h}$. Then a diffraction pattern was collected. Diffraction images were integrated and treated obtaining one-dimensional patterns using the Dioptas program [28].

Structure refinement was performed on the pattern collected at $0.40 \mathrm{GPa}$ in the Cmcm space group using the GSAS package [29] with the EXPGUI [30] interface, starting from the framework atomic coordinates reported in Ref. [23]. The extraframework sites (oxygen atoms of $\mathrm{H}_{2} \mathrm{O}$ molecules and $\mathrm{PhA}$ molecules) were localized through the inspection of the difference Fourier map. The background curve was fitted 
using a Chebyshev polynomial with 24 coefficients. The pseudo-Voigt profile function proposed by Thompson [31] was used with a peak intensity cut-off set to $0.1 \%$ of the strongest peak. Soft-restraints were applied to the $\mathrm{T}-\mathrm{O}(1.60 \AA)$ and $\mathrm{C}-\mathrm{C}$ distances (1.50(2), 1.40(2) and 1.25 (2) $\AA$ for the single, double and triple bonds respectively); the weight was gradually decreased, after the initial stages of refinement, up to a final weight of 50. The isotropic displacement parameters were constrained in the following way: a value for all the tetrahedral cations, a second value for all the framework oxygen atoms, a third value for the carbon atoms and a fourth for water oxygen atoms. Details of the structural refinement are reported in Table 2. Atomic coordinates, occupancy factors, and thermal parameters, along with selected bond distances $(\AA)$ are reported as Supporting Information (Tables 1S and $2 \mathrm{~S}$, respectively). The final observed and calculated powder patterns for HS-MOR $\mathrm{PhA}$ at $0.40 \mathrm{GPa}$ are provided in Fig. S1.

Table 2. Structural refinement parameters of HS-MOR compressed in PhA at 0.40 GPa.

\subsection{GPa}

\section{Space group}

$a(\AA)$

$b(\AA)$

$c(\AA)$

$V\left(\AA^{3}\right)$

$\mathbf{R}_{\mathrm{wp}}(\%)$

$\mathbf{R}_{\mathrm{p}}(\%)$

$\mathbf{R}_{\mathrm{F}}{ }^{2}(\%)$

$\mathbf{N}_{\text {obs }}$

$\mathbf{N}_{\mathrm{var}}$

\section{Cmcm}

18.119 (1)

20.235 (2)

7.4619 (6)

2735.8 (3)

0.1031

0.007

0.10

947

71

\subsubsection{HP-IR}

For investigating HS-MOR/PhA mixtures at high pressures by IR absorption spectroscopy, we used membrane DACs with a diamond culet diameter of $600 \mu \mathrm{m}$ and equipped with stainless steel gaskets. Typical sample diameter and thickness were $200 \mu \mathrm{m}$ and about $50 \mu \mathrm{m}$, respectively. The cell was loaded with pure phenylacetylene as PTM. A ruby chip was also put in the sample chamber for pressure measurements 
[27]. After closing the cell, the liquid hydrocarbon filled both the pores of the zeolite (confined $\mathrm{PhA}$ ), as testified by changes in the relative intensity of $\mathrm{X}$-ray diffraction Bragg peaks of HS-MOR, and the residual empty space between the grains of mordenite (bulk $\mathrm{PhA}$ ). High pressure, IR spectra on $\mathrm{HS}-\mathrm{MOR} / \mathrm{PhA}$ were measured with resolution of $1.0 \mathrm{~cm}^{-1}$, using a Bruker IFS-120 HR Fourier transform infrared spectrometer equipped with an optical beam condenser based on ellipsoidal mirrors [32]. The IR spot diameter is typically larger than the sample diameter and, consequently, the gained information on chemical structure corresponds to the spatial average of this structure over the whole sample size.

\section{Results}

\subsection{Surface area and pores dimensions of pristine HS-MOR}

To obtain information on the pore dimension distribution, HS-MOR sample was characterized by $\mathrm{N}_{2}$ adsorption. The $\mathrm{N}_{2}$ sorption (Fig. 2) follows a type 1 isotherm, typical of a microporous solid, with some specific features. The onset of adsorption at low pressure is less sharp than expected in a purely microporous solid. The presence of a continuous transition between microporosity (diameter lower than $2 \mathrm{~nm}$ ) and small mesoporosity has to be considered in the evaluation of the micropore volume by comparison methods. The $\alpha \mathrm{S}$ plot cannot be linearized below $\alpha \mathrm{S}=1$. As a consequence, the volume of small pores evaluated by this method, $0.22 \mathrm{~cm}^{3} \mathrm{~g}^{-1}$, is not limited to micropores, but it includes all pores with diameter smaller than $4 \mathrm{~nm}$. A DFT analysis of mesopore size distribution indicates a pore volume of $0.021 \mathrm{~cm}^{3} \mathrm{~g}^{-1}$ distributed in the size range $2-4 \mathrm{~nm}$. If this volume is subtracted from the $\alpha \mathrm{S}$ data, the true micropore volume can be evaluated at $0.20 \mathrm{~cm}^{3} \mathrm{~g}-{ }^{-1}$. This continuous transition between micropores and mesopores is expected in a dealuminated commercial sample, as the dealumination procedure is well known to induce defects and to open side communications between side pockets of mordenite. Dealumination methods can also open mesopores with larger size. The total mesopore volume of the sample between 2 and $60 \mathrm{~nm}$ diameter is $0.061 \mathrm{~cm}^{3} \mathrm{gr}^{-1}$, of which 0.037 are widely distributed in the diameter range between 6 and $60 \mathrm{~nm}$. 


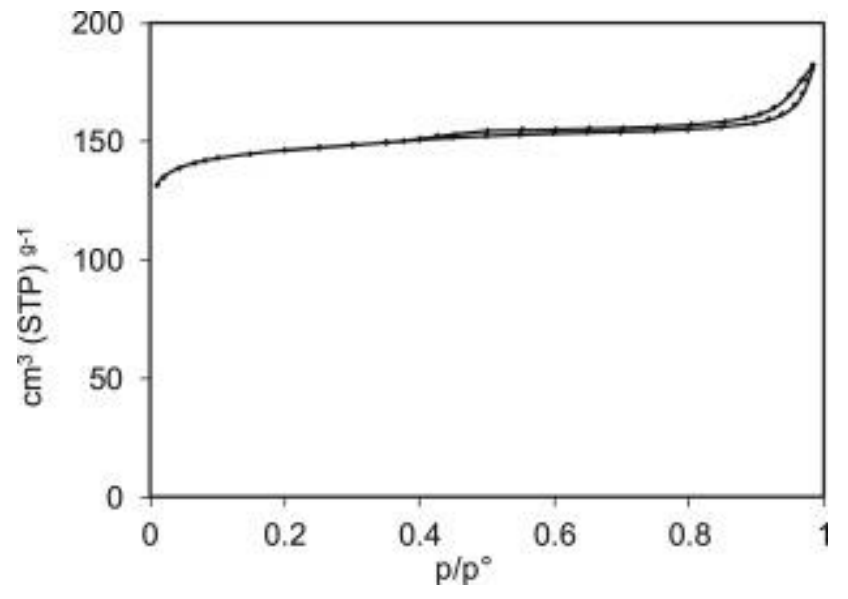

Fig. 2. Adsorption-desorption $\mathrm{N}_{2}$ isotherm at $77 \mathrm{~K}$.

\subsection{X-ray powder diffraction experiments}

To explore the possibility of injecting $\mathrm{PhA}$ inside the HS-MOR pores, a preliminary qualitative test was performed with conventional (Mo K $\alpha$ source) X-Ray powder diffraction (XRPD) in Diamond Anvil Cell (DAC). Fig. 3 reports the patterns collected before and after the contact of the powder with liquid $\mathrm{PhA}$.

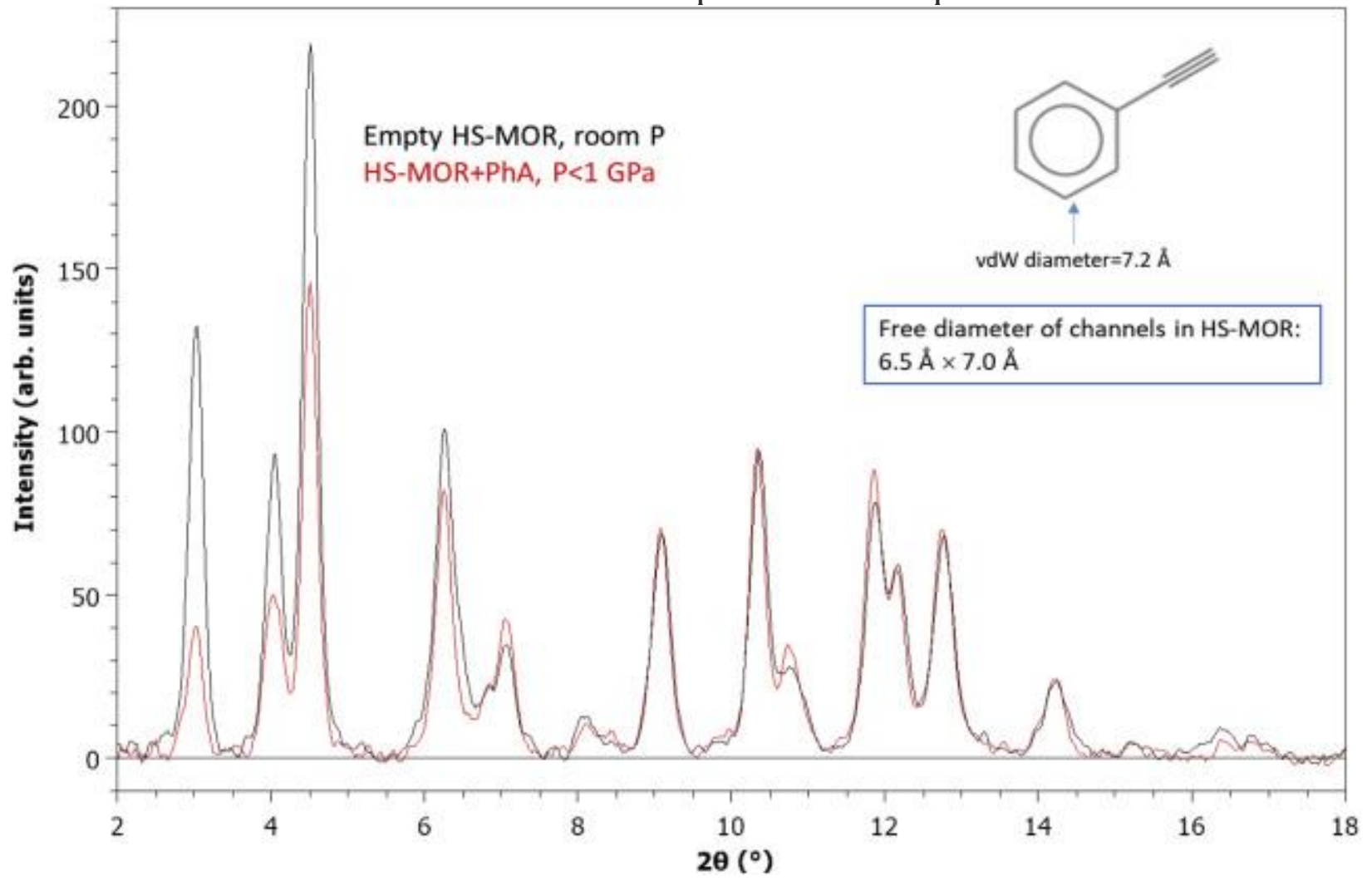

Fig. 3. HS-MOR XRPD patterns measured in a DAC before (black) and after loading liquid PhA (red). A molybdenum X-ray micro-source $(\lambda=0.71073 \AA$ ) has been used. The 
strong Compton background from diamonds and the broad diffuse diffraction pattern from liquid $\mathrm{PhA}$ have been subtracted. The two patterns have been normalized for the same intensity at $9.1^{\circ}-10.3^{\circ}$. (For interpretation of the references to color in this figure legend, the reader is referred to the Web version of this article.)

It is evident that the simple contact between HS-MOR and PhA under very mild pressure conditions (obtained by simply closing the DAC) induces strong changes in the intensity of the low-angle diffraction peaks. Being these peaks strongly influenced by the extraframework content, we can assume that some $\mathrm{PhA}$ molecules are intruded in HS-MOR microporosity. This result is not obvious since the Van der Waals diameter of a PhA molecule is $7.2 \AA$, whereas the nominal $12 \mathrm{MR}$ channel diameter of MOR is $6.5 \times 7.0 \AA$. However, the penetration of species slightly larger than the pores dimension in zeolites at low pressure, or even at ambient pressure $\left(\mathrm{P}_{\text {amb }}\right)$ conditions, has been already demonstrated in a number of studies which pinpointed the key role of both zeolite-flexibility and guest molecule flexibility in the insertion process [[33], [34], [35], [36], [37]]. In particular, also guest species possessing aromatic rings show a surprisingly high flexibility of the molecular structure, which allows for both the encapsulation and the diffusion of these species inside the zeolite channels [38]. An accurate X-ray powder diffraction structural analysis was performed at $0.40 \mathrm{GPa}$. At higher pressures, the bad quality of the data led to unrealistic distances and did not allow a reliable structural refinement. The refinement at $0.40 \mathrm{GPa}$ indicates that the compression of HS-MOR by $\mathrm{PhA}$ leads to an expansion of the unit cell along all the three axes, in comparison to the values measured at ambient pressure (Table 1, Table 2). In particular, the $a$ parameter shows an increase of about $0.30 \%$, while $b$ and $c$ expand by 0.14 and $0.15 \%$, respectively. This anisotropic behaviour of the cell parameters is related to the intrusion and the consequent arrangement of the extraframework molecules in the porosities.

As a whole, 2 molecules of $\mathrm{PhA}$ per unit cell, distributed over 4 equivalent sites, were located in the $12 \mathrm{MR}$ channels (Table 1, Table 2S). The molecules, on average, are parallel and lie near the center of the channel on two equivalent planes parallel and close to the (020) plane. This induces a larger increase of the $a$ lattice parameter. Despite PhA molecules can be sited over 4 equivalent sites (two in each $12 \mathrm{MR}$ channel), the too short distance (1.8300 (1) ^) between two carbon-cycles belonging to two different molecules suggests the distribution of the two phenylacetylene 
molecules into two different channels. For each molecule, phenyl sites $\left(\mathrm{C}_{1} \mathrm{~h}_{1}\right.$ and $\mathrm{C} 2 \mathrm{~h}_{2}$, see $\underline{\text { Fig. }}$. a) are uniquely located, while the position of the $\mathrm{C} \equiv \mathrm{CH}$ acetylenic moiety has four possible crystallographically equivalent orientations $\left(\mathrm{C} 31_{1}\right.$ and $\mathrm{C}_{4} \mathrm{l}_{2}$ carbon atoms in Fig. 4a). Fig. $4 \mathrm{~b}$ and c shows the average refined structure, reporting two possible $\mathrm{PhA}$ molecule configurations inside the mordenite microporosities. Along with the $\mathrm{PhA}$ molecules, $3.2 \mathrm{H}_{2} \mathrm{O}$ molecules were localized in the side-pockets between the 12 and $8 \mathrm{MR}$ channels. From the structural model obtained, it is possible to conclude that $\mathrm{PhA}$ monomers at $0.40 \mathrm{GPa}$ have very weak interaction with the zeolite framework.
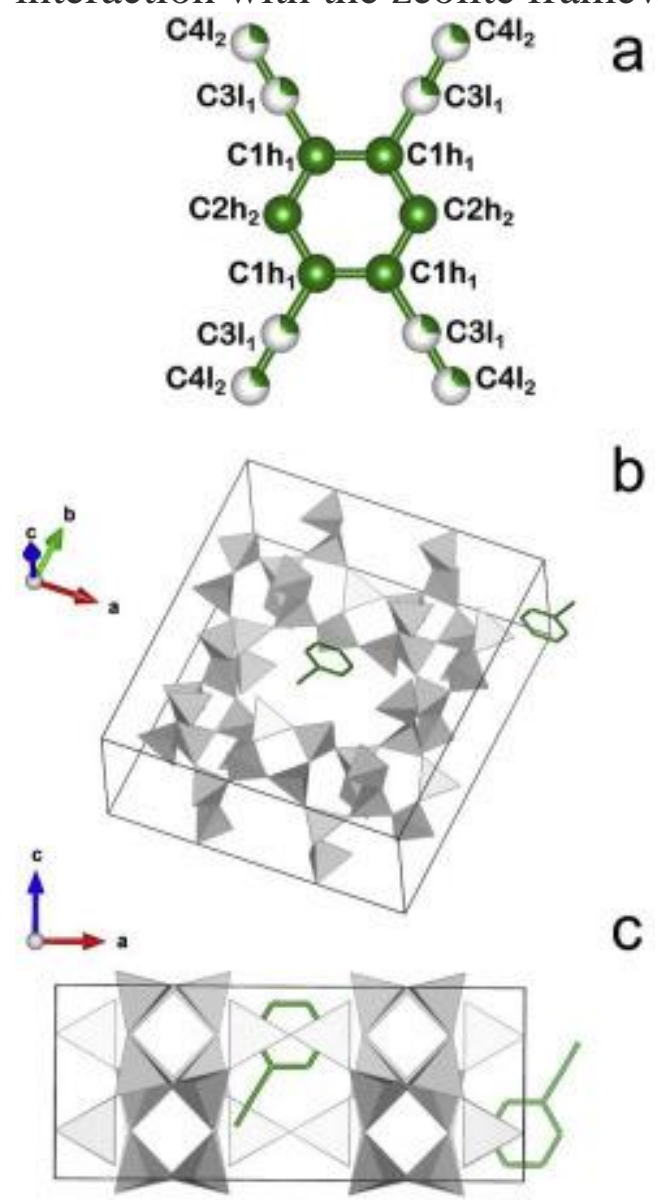

Fig. 4. a) Phenylacetylene molecule showing the labels used for the carbon sites. b) and c) Structural model of HS-MOR compressed in phenylacetylene at $0.40 \mathrm{GPa}\left(\mathrm{H}_{2} \mathrm{O}\right.$ molecules are omitted for clarity). The two figures show only the average positions actually occupied rather than all the partially occupied symmetrically equivalent positions.

As shown in Fig. 5, upon pressure increase, the relative intensity of the diffraction peaks changes, indicating further intrusion of phenylacetylene. Unfortunately, the 
high disorder affecting the extraframework species does not allow to localize the $\mathrm{PhA}$ molecules in the channels. After the compression at $1.34 \mathrm{GPa}$, the DAC was kept in oven at $150{ }^{\circ} \mathrm{C}$ for $5 \mathrm{~h}$ (high temperature treatment, HT hereafter). Upon heating, the pressure reached $2.58 \mathrm{GPa}$, whereas in the room temperature (r.t.) quenched sample, the pressure returned to the pristine value of $1.35 \mathrm{GPa}$. The powder diffraction pattern collected after the HP-HT treatment shows new slight differences in the peak intensity and in their ratio with respect to the pattern collected at r.t. (Fig. 5). Due to the strong peak broadening, no further consideration can be made on the evolution of the cell parameters. Indeed, the cell parameters values at $1.34 \mathrm{GPa}(a=18.05$ (8) $\AA, b=18.0$ (1) $\AA, c=7.40$ (5) $\left.\AA, V=2670(28) \AA^{3}\right)$ and after thermal treatment ( $a=18.1$ (2) $\AA, b=20.0$ (3) $\AA, c=7.4$ (1) $\AA, V=2675$ (56) $\AA^{3}$ ) are affected by very high standard deviations, which do not allow to appreciate any differences between the two sets.

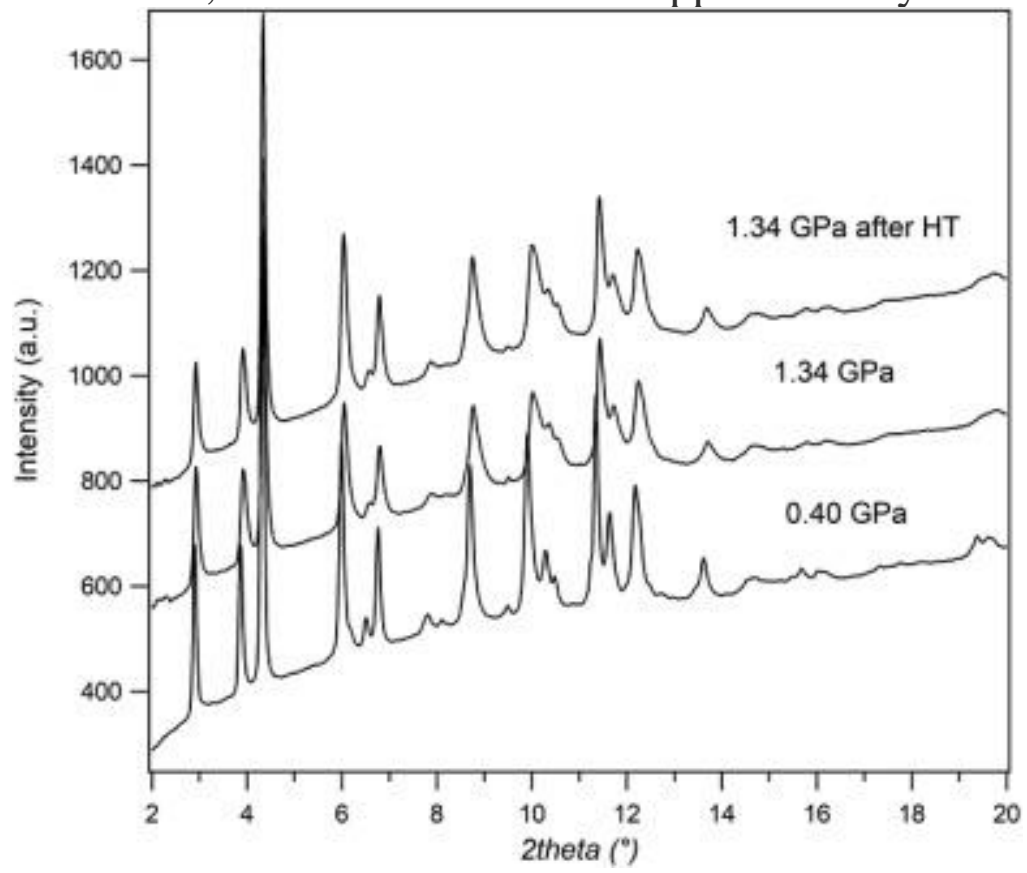

Fig. 5. Diffraction patterns of HS-MOR compressed in phenylacetylene at $0.40 \mathrm{GPa}$, $1.34 \mathrm{GPa}$ and at $1.34 \mathrm{GPa}$ after HT treatment.

\subsection{Infrared spectroscopy investigation}

In Fig. 6, we report selected high pressure IR absorption spectra of HS-MOR/PhA mixtures and of pure $\mathrm{PhA}$, measured along similar P-T paths. 


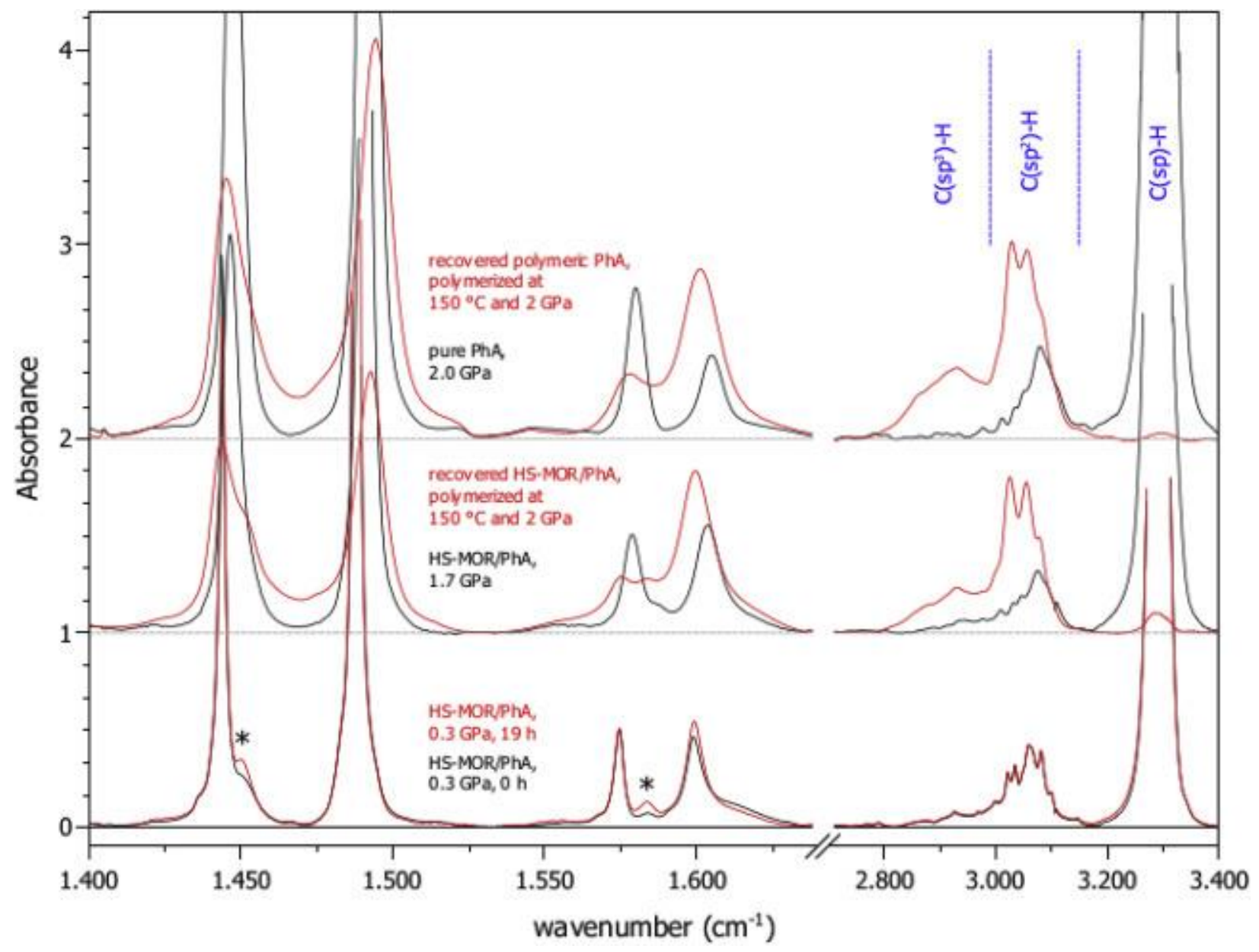

Fig. 6. Selected, high pressure IR absorption spectra of HS-MOR/PhA mixtures and of pure $\mathrm{PhA}$. Bottom: spectra of a HS-MOR/PhA sample at $0.30 \mathrm{GPa}$, freshly loaded in DAC (black) and after $19 \mathrm{~h}$ (red). Stars indicate short oligomers formed as a function of time. Middle: spectra of the same sample at $1.70 \mathrm{GPa}$ (black) and of the recovered sample at ambient conditions (red), after polymerization of $\mathrm{PhA}$ obtained in about $13 \mathrm{~h}$ at $150{ }^{\circ} \mathrm{C}$ and $2.00 \mathrm{GPa}$. Top: spectra of a pure $\mathrm{PhA}$ sample at $2.00 \mathrm{GPa}$ (black) and of the recovered sample at ambient conditions (red), after polymerization obtained in about $18 \mathrm{~h}$ at $150{ }^{\circ} \mathrm{C}$ and $2.00 \mathrm{GPa}$. Spectral intervals for peaks due $\mathrm{C}\left(\mathrm{sp}^{3}\right)-\mathrm{H}, \mathrm{C}\left(\mathrm{sp}^{2}\right)-\mathrm{H}$ and $\mathrm{C}$ (sp) $-\mathrm{H}$ stretching modes are also labeled in blue. An absorption spectrum of pure HSMOR measured at ambient pressure in DAC has been subtracted from all the spectra of HS-MOR/PhA. (For interpretation of the references to color in this figure legend, the reader is referred to the Web version of this article.)

The IR investigation on the high pressure - high temperature polymerization of pure $\mathrm{PhA}$ here serves as a reference background to interpret analogous results on HSMOR/PhA mixtures. Pure PhA solidifies above $1.10 \mathrm{GPa}$ forming a molecular solid and it does not polymerize below $8.00 \mathrm{GPa}$ at room temperature [39]. On the other 
hand, here we found that high temperature severely enhances the high pressure polymerization of $\mathrm{PhA}$. Indeed, solid $\mathrm{PhA}$ at $2.00 \mathrm{GPa}$ is chemically stable (Fig. 6, top spectra) over days at least, whereas heating the sample to $150{ }^{\circ} \mathrm{C}$ at nearly the same pressure for $18 \mathrm{~h}$ results in almost the $100 \%$ polymerization of the starting monomer. This occurs likely because the sample is melted and the mass diffusivity and chemical reactivity are increased. The material recovered after the HP-HT treatment is polyPhA, a red solid material. This polymer is made of a skeletal conjugated carbon chain, where conjugation relates to the red color, while the phenyl groups are chemically unaffected by the polymerization reaction [39]. Monomeric and polymeric $\mathrm{PhA}$ exhibit IR peaks at rather similar frequencies in the $1400-1650 \mathrm{~cm}^{-1}$ range, although relative intensities and line-shapes of those peaks substantially differ for the two species. The $\mathrm{C}-\mathrm{H}$ stretching peaks at $2800-3400 \mathrm{~cm}^{-1}$ are a direct easy probe for the carbon coordination changes in going form the monomer to the polymer. Indeed, the very strong $\equiv \mathrm{C}(\mathrm{sp})-\mathrm{H}$ stretching peak of the monomer at $3300 \mathrm{~cm}^{-1}$ is drastically reduced in intensity during the thermal treatment and it is hardly visible in the polymer, showing that the polymerization is almost complete. This is accompanied by a substantial intensity increase in the $3000-3150 \mathrm{~cm}^{-1}$ frequency range where $\mathrm{C}-\mathrm{H}$ stretching vibrations from $\mathrm{sp}^{2}$ carbon are typically found, and we interpret this increase mostly with the formation of the conjugated $-\mathrm{C}=\mathrm{C}$ - skeleton system of polyPhA. The $\mathrm{C}-\mathrm{H}$ stretching IR peak of this skeleton partially overlaps to those of the aromatic phenyl groups. Then, an intensity increase in the $2800-3000 \mathrm{~cm}^{-1}$ region is also observed during the thermal treatment, due to $\mathrm{C}-\mathrm{H}$ stretching modes of saturated $\mathrm{sp}^{3} \mathrm{C}$ defects, which always form together with the conjugated polymer. Fig. 6 (bottom) shows selected IR spectra of a HS-MOR/PhA sample sealed at $0.30 \mathrm{GPa}$, a pressure where $\mathrm{PhA}$ is a liquid monomer. Spectra measured over a time interval of about $19 \mathrm{~h}$ show the slow formation of new peaks, labeled by asterisks in the figure, which belong neither to monomeric nor to polymeric $\mathrm{PhA}$. These peaks can be assigned to short carbo-cationic oligomers probably formed as a result of the catalytic action of mordenite. In fact, these peaks do not appear in the pure PhA sample. Anyway, the catalyzed reaction of PhA is at a very initial stage after $19 \mathrm{~h}$ and the vast majority of initial monomeric $\mathrm{PhA}$ is still present, as shown by the strong, always saturating $\mathrm{C}$ (sp)-H stretching peak of monomeric $\mathrm{PhA}$ at $3300 \mathrm{~cm}^{-1}$. The sample was then compressed at $1.70 \mathrm{GPa}$ (Fig. 6, middle, black spectrum), above the 
solidification pressure of $\mathrm{PhA}$, and the polymerization stopped entirely over a probing time interval of about $24 \mathrm{~h}$, probably because of the solidification related drop of mass diffusivity, which hinders the reactivity of the monomer. Finally, the HS-MOR/PhA sample was brought to the same $\mathrm{P}-\mathrm{T}$ conditions of pure $\mathrm{PhA}$ (i.e. $150{ }^{\circ} \mathrm{C}$ at $2.00 \mathrm{GPa}$, for $13 \mathrm{~h}$ ) (Fig. 6, middle, red spectrum) and the $\mathrm{PhA}$ component of the mixture polymerized almost entirely, probably because of the melting related increase of mass diffusivity of $\mathrm{PhA}$, as discussed above. The IR spectrum of the mixed recovered sample, whose picture is reported in Fig. 7, is rather similar to that of polymeric pure $\mathrm{PhA}$.

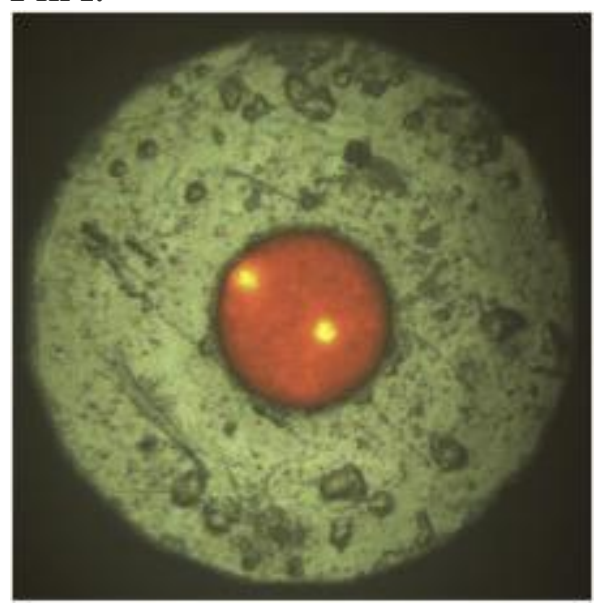

Fig. 7. Picture of HS-MOR/PhA (red sample in the center of the metallic gasket) at almost ambient pressure after the high $\mathrm{P}-\mathrm{T}$ polymerization of $\mathrm{PhA}$ described in the text. The orange/yellow chips within the sample are the rubies used for measuring pressure. The gasket diameter is $600 \mu \mathrm{m}$ and the sample is illuminated both by transmitted and reflected light. (For interpretation of the references to color in this figure legend, the reader is referred to the Web version of this article.)

\section{Discussion and conclusion}

The experiments performed indicated that, despite the larger dimensions with respect to the zeolite pore openings, phenylacetylene molecules can indeed enter the mordenite pores even at very low pressure (almost $\mathrm{P}_{\mathrm{amb}}$ ). The increase of the pressure favors the further penetration of the molecules in the microporosity and, as shown by the X-ray diffraction data, it is possible to conclude that at $0.40 \mathrm{GPa}$, on average, two phenylacetylene molecules are hosted in each mordenite unit cell. This number is lower with respect to that estimated on the basis of the steric hindrance of the guest 
molecules. Such a result can be understood by noting that the diffusion of species of size comparable to the pores openings - such as PhA in HS-MOR - is slowed down by the so-called "traffic jam" effect - i.e. the crowding of molecules close to zeolite pore entrances [37]. This effect may be overcome by HP: indeed, further penetration of $\mathrm{PhA}$ molecules occurs upon pressure increase, as witnessed by the changes in the relative intensities of X-ray diffraction peaks. However, probably due to the statistical disorder in the pores at higher pressure (and evidenced by the worsening of the diffraction pattern with compression) it has not been possible to quantify the maximum number of molecules at the highest investigated pressure.

In the absence of a detailed structural investigation, spectroscopic data gave important clues to unravel the evolution of the system at higher pressure. In fact, IR spectra suggest a slow oligomerization reaction, observed at $0.30 \mathrm{GPa}$, forming short carbocationic oligomers. These species do not form in the pure PhA sample at the same conditions, so they should result from the interaction with mordenite that catalyzes the reaction. The limited spatial resolution of the experiment did not allow to distinguish between the PhA present inside or outside the mordenite framework; on the other hand, from the IR spectra, we clearly found that the vast majority of initial monomeric $\mathrm{PhA}$ is still present at $0.30 \mathrm{GPa}$. Oligomer molecules were not detected by HP-XRPD, firstly because these oligomers form disordered arrays, and diffraction can offer only average structures, and secondly because the oligomerization kinetics is much slower (hours) than the data collection time (minutes).

Once the applied pressure reaches that of PhA solidification ( 1.10 GPa), the molecular system freezes and in order to observe further evolution of the system higher temperature is needed: once the PhA molecular solid formed in the gasket melts upon heating, it is possible to observe further reactivity and the complete polymerization of $\mathrm{PhA}$ into poly-phenylacetylene. Once again it is not possible to distinguish between the IR signals coming from the zeolites + $\mathrm{PhA}$ (polyPhA) hybrid and from the pure polyPhA present inter - grains, even if it is possible to conclude the $\mathrm{PhA}$ is completely consumed in favour to the polymer both inside and outside the mordenite porosities. In fact, it is worth noting that if monomer would be still present (inside or outside the mordenite pores), the IR C-H stretching peak at $3300 \mathrm{~cm}^{-1}$ would be very intense. 
Interestingly, despite the choice of a zeolite characterized by a mono-dimensional channel system, the IR spectra measured on the polymerized samples indicated the presence of somewhat branched, conjugated polymers, rather than ideally linear, fully conjugated polymers. This is clearly due to the presence of a certain degree of mesopores in the starting zeolites: the de-alumination procedure, aimed at the obtainment of a high silica phase, is well known to induce strong defectivity, leading to a non-perfectly mono dimensional structure. Anyway, it is worth noting that at least part of the polyPhA we observe through IR - i.e portions of conjugated oligomers can also be allocated within the mesopores of HS-MOR. Hence, we can conclude that the combined action of HP and space confinement has produced a zeolite-based composite material in which the guest species have a degree of conjugation greater than the starting monomer, as witnessed by the red color of the recovered sample. This evidence holds promises for the realization of new materials with intriguing optoelectronic properties via pressure-driven polymerization of aromatic molecules inside zeolite cages. Further studies will be aimed to obtain a linear conjugated polymer in a non-defective framework characterized by monodimensional channel system.

\section{CRediT authorship contribution statement}

Giorgia Confalonieri: Investigation, Data curation, Writing - original draft. Marco Fabbiani: Investigation, Writing - original draft. Rossella Arletti: Conceptualization, Methodology, Investigation, Writing - original draft, Writing - review \& editing, Supervision, Project administration, Funding acquisition. Simona

Quartieri: Methodology, Writing - review \& editing, Funding acquisition. Francesco Di Renzo: Methodology, Conceptualization. Julien Haines: Conceptualization, Writing - review \& editing. Gloria Tabacchi: Methodology, Writing - review \& editing. Ettore Fois: Methodology, Writing - review \& editing. Giovanna Vezzalini: Methodology, Writing - review \& editing, Funding acquisition. Gianmario Martra: Methodology, Writing - review \& editing. Mario Santoro: Conceptualization, Investigation, Methodology, Writing - original draft, Writing - review \& editing, Funding acquisition. 


\section{Declaration of competing interest}

The authors declare that they have no known competing financial interests or personal relationships that could have appeared to influence the work reported in this paper.

\section{Acknowledgement}

This work was carried put in the frame of the PRIN project ZAPPING (PRIN2015 Prot. 2015HK93L7) funded +by the Italian MIUR. The authors thank the staff of SNBL1 (BM01) beamline at ESRF (Grenoble, France), for the assistance during XRPD data collection.

\section{References}

B.M. Weckhuysen, J.H. Yu

Chem. Soc. Rev., 44 (2015), pp. 7022-7024

[2]

J. Čejka, A. Corma, S. ZonesZeolite and Catalysis. Synthesis, Reactions and Applications

Wyley-YCH, Weinheim (2010) [3]

R. Xu, W. Pang, J. Yu, Q. Huo, J. ChenChemistry of Zeolites and Related Porous Materials: Synthesis and Structure

John Wiley \& Sons (Asia) Pte Ltd. (2007)

[4]

R.P. Townsend, E.N. CokerIon exchange in zeolites

H. van Bekkum, E.M. Flanigen, P.A. Jacobs, J.C. Jansen (Eds.), Introduction to Zeolite Science and Practice, Elsevier, Amsterdam ; New York (2011)

[5]

G.D. Gatta, P. Lotti, G. Tabacchi

Phys. Chem. Miner., 45 (2018), pp. 115-138

G. Tabacchi

\section{[6]}

ChemPhysChem, 19 (2018), pp. 1249-1297

N.C. Jeong, H.S. Kim, K.B. Yoon 
Langmuir, 21 (2005), pp. 6038-6047

[8]

R. Garcia, V. Martinez-Martinez, R.S. Llano, I. Lopez-Arbeloa, J. Perez-Pariente

J. Phys. Chem. C, 117 (2013), pp. 24063-24070

[9]

L. Gigli, R. Arletti, G. Tabacchi, E. Fois, J.G. Vitillo, G. Martra, G. Agostini, S. Quartieri , G. Vezzalini

J. Phys. Chem. C, 118 (2014), pp. 15732-15743

H. Maas, A. Currao, G. Calzaferri

Angew. Chem. Int. Ed., 41 (2002), pp. 2495-2497

P. Woodtli, S. Giger, P. Muller, L. Sagesser, N. Zucchetto, M.J. Reber, A. Ecker, D. Bruh wiler

Dyes Pigments, 149 (2018), pp. 456-461

R. Arletti, E. Fois, L. Gigli, G. Vezzalini, S. Quartieri, G. Tabacchi

Angew. Chem. Int. Ed., 56 (2017), pp. 2105-2109

G. Confalonieri, S. Quartieri, G. Vezzalini, G. Tabacchi, E. Fois, T.J. Daou, R. Arletti

Microporous Mesoporous Mater., 284 (2019), pp. 161-169

M. Santoro, F.A. Gorelli, R. Bini, J. Haines, A. van der Lee

Nat. Commun., 4 (2013), pp. 3761-3767

D. Scelta, M. Ceppatelli, M. Santoro, R. Bini, F.A. Gorelli, A. Perucchi, M. Mezouar, A. van der Lee, J. Haines 
Chem. Mater., 26 (2014), pp. 2249-2255

M. Santoro, D. Scelta, K. Dziubek, M. Ceppatelli, F.A. Gorelli, R. Bini, G. Garbarino, J. M. Thibaud, F. Di Renzo, O. Cambon, P. Hermet, J. Rouquette, A. van der Lee, J. Haines Chem. Mater., 28 (2016), pp. 4065-4071

H. Bassler

Nat. Phys., 2 (2006), pp. 15-16

D.J. Cardin

Adv. Mater., 14 (2002), pp. 553-563

P.T. Moseley, D.E. WilliamsTechniques and Mechanism in Gas Sensing Adam Hilger, Bristol, UK (1991)

C. Baerlocher, L.B. McCusker, D.H. OlsonAtlas of Zeolite Framework Types (sixth ed.), Elsevier, Amsterdam, The Netherlands (2007)

W.M. Meier

Z. für Kristallogr. - Cryst. Mater., 115 (1961), pp. 439-450 
A. Martucci, L. Pasti, M. Nassi, A. Alberti, R. Arletti, R. Bagatin, R. Vignola, R. Sticca Microporous Mesoporous Mater., 151 (2012), pp. 358-367

R. Arletti, L. Leardini, G. Vezzalini, S. Quartieri, L. Gigli, M. Santoro, J. Haines, J. Rouq uette, L. Konczewicz

Phys. Chem. Chem. Phys., 17 (2015), pp. 24262-24274

R. Fantini, R. Arletti, S. Quartieri, M. Fabbiani, S. Morandi, G. Martra, F. Di Renzo, G. Vezzalini

Microporous Mesoporous Mater. (2019), p. 294

R. Miletich, D.R. Allan, W.F. KushHigh temperature and high-pressure crystal chemistry

R.M. Hazen, R.T. Downs (Eds.), Reviews in Mineralogy and

Geochemistry, Mineralogical Society of America and Geochemical Society

Washington, USA (2000), pp. 445-519

R.A. Forman, G.J. Piermarini, J.D. Barnett, S. Block

Science, 176 (1972), pp. 284-285

K.H. Mao, J. Xu, P.M. Bell 
J. Geophys. Res., 91 (1986), p. 4673

C. Prescher, V.B. Prakapenka

High Pres. Res., 35 (2015), pp. 223-230

\section{C.A.R.B. LarsonVon Dreele}

Los Alamos National Laboratory Report (1994)

\section{B.H. Toby}

J. Appl. Crystallogr., 34 (2001), pp. 210-213

P. Thompson, D.E. Cox, J.B. Hastings

J. Appl. Crystallogr., 20 (1987), pp. 79-83

F.A. Gorelli, L. Ulivi, M. Santoro, R. Bini

Phys. Rev. Lett., 83 (1999), pp. 4093-4096

G. Calzaferri, S. Huber, H. Maas, C. Minkowski

Angew. Chem. Int. Ed., 42 (2003), pp. 3732-3758 
G. Tabacchi, E. Fois, G. Calzaferri

Angew. Chem. Int. Ed., 54 (2015), pp. 11112-11116

G. Tabacchi, G. Calzaferri, E. Fois

Chem. Commun., 52 (2016), pp. 11195-11198

L. Gigli, R. Arletti, G. Tabacchi, M. Fabbiani, J.G. Vitillo, G. Martra, A. Devaux, I. Milet to, S. Quartieri, G. Calzaferri, E. Fois

J. Phys. Chem. C, 122 (2018), pp. 3401-3418

M. Busby, A. Devaux, C. Blum, V. Subramaniam, G. Calzaferri, L. De Cola

J. Phys. Chem. C, 115 (2011), pp. 5974-5988

E. Fois, G. Tabacchi, G. Calzaferri

J. Phys. Chem. C, 116 (2012), pp. 16784-16799

M. Santoro, L. Ciabini, R. Bini, V. Schettino

J. Raman Spectrosc., 34 (2003), pp. 557-566 
